\title{
RNA Chemistry for RNA Biology
}

\author{
Pascal Röthlisberger, Christian Berk, and Jonathan Hall ${ }^{\star c}$
}

\begin{abstract}
Advances in the chemical synthesis of RNA have opened new possibilities to address current questions in RNA biology. Access to site-specifically modified oligoribonucleotides is often a pre-requisite for RNA chemical-biology projects. Driven by the enormous research efforts for development of oligonucleotide therapeutics, a wide range of chemical modifications have been developed to modulate the intrinsic properties of nucleic acids in order to fit their use as therapeutics or research tools. The RNA synthesis platform, supported by the NCCR RNA \& Disease, aims to provide access to a large variety of chemically modified nucleic acids. In this review, we describe some of the recent projects that involved work of the platform and highlight how RNA chemistry supports new discoveries in RNA biology.
\end{abstract}

Keywords: RNA chemistry - NCCR synthesis platform - RNA therapeutics \& tools - Click chemistry · Phosphorothioates · Convertible nucleoside approach ·

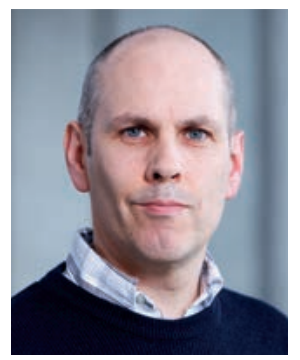

Jonathan Hall received his $\mathrm{PhD}$ in organic chemistry at Imperial College in London. He did post-doctoral work with J.-M. Lehn in Strasbourg (FR) and with Y. Kishi in Cambridge (USA). He joined the nucleic acids section at Novartis Pharmaceuticals in Basel in 1992. In the following six years his group established high-throughput oligonucleotide synthesis and genome-wide screening using siRNAs. Together with colleagues from the neuroscience department they developed methods to use siRNAs in vivo which resulted in therapeutic effects of siRNAs in clinical models of neuropathic pain. Jonathan Hall became full professor for Pharmaceutical Chemistry at the ETHZ in 2007. From 2012-2014 he was chair of the Institute of Pharmaceutical Sciences. Jonathan Hall serves on the steering committee of the Drug Discovery Network Zurich (DDNZ), of which he is a co-founder. Currently, he manages a 15 -member group comprising graduate students and post-doctoral fellows. The long-term objective of his group is to increase the drugability of RNA with new classes of oligonucleotide- and small molecule-ligands.

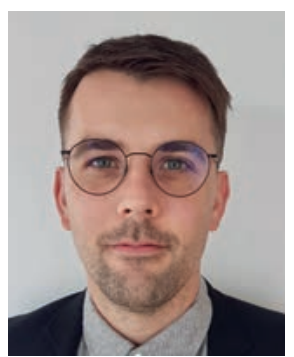

Pascal Röthlisberger was trained as a chemistry technician at Hoffmann-la Roche in Basel from 2001 to 2004. Afterwards he obtained his BSc, MSc and his PhD at the University of Bern under the supervision of Prof. Dr. C. J. Leumann. His PhD project concerned the study of reductive electron transfer through phenanthrenyl modified DNA. After completion of his PhD in 2016 he started a postdoc at the Pasteur Institute Paris where he worked on the synthesis and application of chemically modified dNTPs for systematic evolution experiments under the guidance of Dr. M. Hollenstein. In 2018 he joined the group of Prof. Dr. J. Hall at the Federal Institute of Technology Zurich (ETH) to work on pharmaceutical RNAs. Currently he also serves as the head of the RNA synthesis platform of the NCCR RNA \& Disease.

${ }^{\star}$ Correspondence: Prof. Dr. J. Hall

E-mail: jonathan.hall@pharma.ethz.ch

ETH Zurich, Institute of Pharmaceutical Science (IPW), Vladimir-Prelog-Weg 1-5/10, $\mathrm{CH}-8093$ Zürich

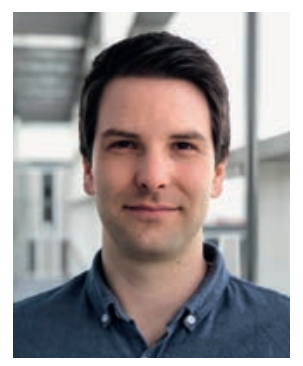

Christian Berk studied pharmacy at the University of Freiburg. In 2013 he joined the group of Prof. Dr. P. F. Leadlay at the University of Cambridge to conduct his diploma thesis on polyketide natural products and completed his training as a pharmacist in 2014. During his studies he gained experience in the fields of technical R\&D and pharmacovigilance through internships at LTS Lohmann and Sanofi. In 2015 he joined the group of Prof. Dr. J. Hall at the Federal Institute of Technology Zurich (ETH) where he currently pursues his PhD in nucleic acid chemistry. In his research he focusses on the development of alternative scaffolds for RNA therapeutics.

\section{Introduction}

Oligonucleotide-based therapeutics have created enormous excitement since the first observation that a DNA that was antisense to a viral RNA could be used to reduce protein expression and replication of Rous sarcoma virus. ${ }^{[1]}$ Fuelled by mechanistic studies on antisense oligonucleotides and the discovery of the RNA interference pathway, the field is currently witnessing the approval of chemically- and functionally-diverse oligonucleotide drugs. ${ }^{[2]}$ In parallel, advances in RNA chemistry have provided key tools that have enabled the stepwise discovery of a highly complex network of regulatory small and long non-coding RNAs as well as their interplay with a multitude of RNA binding proteins. ${ }^{[3]}$ Although the field of RNA biology has come a long way, our understanding of the intriguing roles RNA plays inside cells is still far from complete. The Swiss National Science Foundation (SNSF) has combined efforts of individual research groups with a common focus on RNA under the umbrella of the National Center of Competence in Research (NCCR), RNA and Disease (https://nccr-rna-and-disease.ch). The mission of the RNA Synthesis Platform in this NCCR is to provide access to unique oligonucleotide tools and analytics that enable new discoveries in the RNA field. We also conduct research to continuously expand our portfolio of modified nucleic acids to offer unique solutions, tailored to individual research needs.

\section{Modifications of the Phosphodiester Backbone}

The RNA scaffold is defined by the sugar-phosphate backbone which acts as an anchor for the nucleobases. The phosphodiester backbone also serves as a well-accessible and favourable site for chemical modification (Fig. 1). Thus, various backbone modifi- 


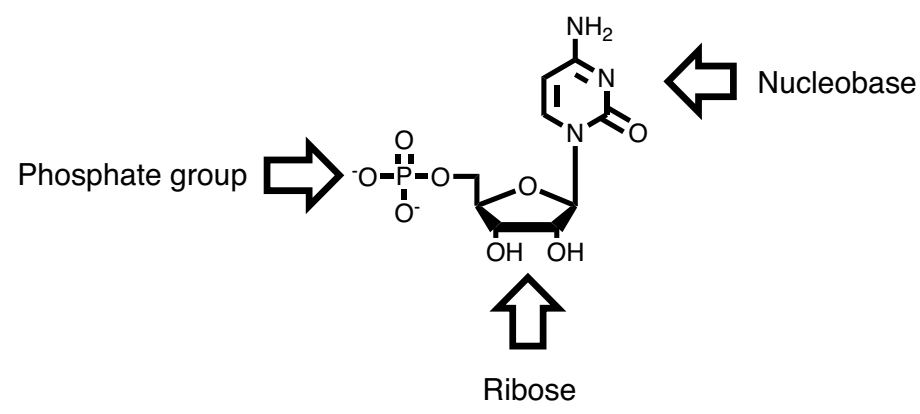

Fig. 1. Sites of common RNA modifications.

cations have been developed to modulate hybridization affinity, nuclease resistance and protein binding (reviewed in refs [2b,4]) or for the functionalization with cross-linking groups. ${ }^{[5]}$ The most prominent backbone modification is the substitution of one of the non-bridging oxygens of a 5'-3'-phosphodiester linkage with sulphur. The incorporation of phosphorothioate (PS) bonds increases their resistance to nuclease cleavage and in the case of single-stranded oligonucleotides, their binding to serum proteins. ${ }^{[6]}$ To improve systemic delivery most antisense therapeutics exploit transient binding to carrier proteins such as serum albumin through a full PS backbone. ${ }^{[4]}$ Nevertheless, the introduction of asymmetric backbone modifications adds an additional layer of complexity to RNA as each substitution converts a prochiral phosphodiester into a new stereocenter and leads to the formation of $2^{\mathrm{n}}$ diastereoisomers $(\mathrm{n}=$ number of linkages $)^{[7]}$ unless chiral auxiliary groups are employed for stereospecifc synthesis. ${ }^{[8]}$ The introduction of such phosphoroamidites has permitted stereopure versions of clinically-validated methoxyethyl (MOE) and locked nucleic acid (LNA) chemistries. However, the synthesis of stereopure phosphorothioate antisense and splice switching oligonucleotides (SSO) is a challenge for the field, particularly at a commercial scale. SSOs are a class of antisense therapeutics that are designed to correct splicing defects by steric blocking of aberrant splice sites. As part of an NCCRfunded effort to tackle erythropoietic protoporphyria (EPP), a rare genetic disease caused by a single nucleotide polymorphism that leads to missplicing of the ferrochelatase $(F E C H)$ transcript, we have reported the first fully-stereopure 2'-O-(2-methoxyethyl)phosphorothioate (PS-MOE) SSO to restore correct splicing. ${ }^{[8 \mathrm{a}]} \mathrm{We}$ demonstrated that a PS-MOE SSO consisting solely of $R \mathrm{p}$ linkages had a higher hybridization affinity compared to its all $S p$ counterpart and that the higher affinity translated into improved splice correction of the $F E C H$ gene in a mini-gene assay in COS7 cells. ${ }^{[8 a]}$

\subsection{3'-Terminal Phosphates}

In addition to the internucleosidic linkages, both termini of the RNA have been used to introduce functional groups for ana- lytical purposes. As an example, 3'-phosphorothioatemonoesters have served for template-dependent chemical ligations (Fig. 2). ${ }^{[9]}$ Appropriately-modified controlled-pore glass (CPG) solid supports offer a convenient means to introduce these groups. As RNA-based, fully-modified splice-switching- and antimiRoligonucleotides advance in the clinic ${ }^{[10]}$ and as the spectrum of chemical modifications expands, a repertoire of reliable quantification techniques becomes essential. Stem-loop RT-qPCR for example, a standard technique in molecular biology to quantify small RNAs, works well for $2^{\prime}-\mathrm{OMe} / 2^{\prime}-\mathrm{F}$ modified siRNAs ${ }^{[11]}$ but is not suitable for $2^{\prime}-\mathrm{MOE}$ antisense therapeutics, ${ }^{\left[{ }^{9 b}\right]}$ the mainstay of single-stranded therapeutics. One possibility to circumvent the enzymatic conversion of RNA to DNA, an essential step in qPCR based methods, is to generate the DNA by a template-dependent chemical-ligation between a 3'-PS-terminated- and a 5'-biphenylsulfonyl (BPS)-capped DNA fragment.[9b] Following the protocol of Boos et al., ${ }^{[9 b]}$ we used chemical ligation qPCR (CLqPCR) to measure antimiR-122 delivery to cells and uptake into the microRNA (miRNA)-induced silencing complex (miRISC) to analyze different patterns of antimiR modifications. ${ }^{[9 c]}$ This showed that even though lipid-nanoparticle mediated delivery to the cytosol was comparable between all tested antimiRs, miRISC uptake was markedly impaired for oligonucleotides with large 2 '-substituents opposite to position 6 of the miRNA target. These findings could be rationalized in view of the crystal structure of Ago2 bound to a RNA duplex. ${ }^{[12]}$ The close association of specific amino acid residues with the 2'-position of the antimiR at this position suggests that a steric clash prevented efficient RISC uptake, in line with a reduced activity of these conjugates. We are currently using CL-qPCR to analyze the cellular delivery of SSOs in continuation of our NCCR-supported efforts to find novel treatments for EPP.

In addition to 3'-phosphatemonoesters, 2'3'-cyclic phosphate terminated RNAs (RNA>p, reviewed in ref. [13]) have a central role in tRNA splicing, ${ }^{[14]}$ snRNA 3'-uridylation ${ }^{[15]}$ and as intermediates in RNAse cleavage reactions. ${ }^{[16]}$ Recently we used a new commercially-available solid support to synthesize A6>p, ${ }^{[17]}$ which aided in the identification of cyclic oligoadenylates as a novel class of second messengers in type III CRISPR Cas systems (Fig. 3). ${ }^{[18]}$ Specifically, head-to-head comparison of synthetically-prepared A6 $>p$ with the natural signaling molecule in enzymatic assays combined with LC/ MS analysis pointed towards cyclic oligoadenylates as second messengers.

\subsection{5'-Terminal Phosphates}

Chemical 5'-phosphorylation of synthetic RNAs and their use in enzymatic ligation reactions has been recognized as a viable route for obtaining long RNAs with site-specific modifications. In an attempt to develop a chemical phosphorylation reagent that
A)

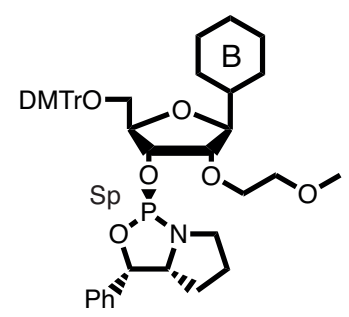

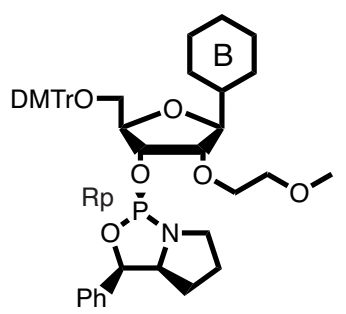

B)

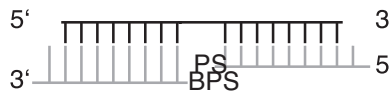

Template mediated ligation

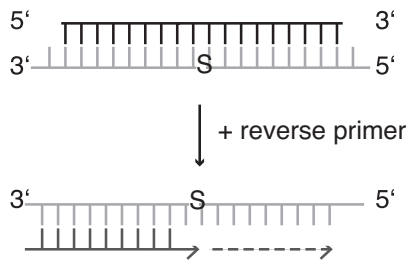

+ forward primer

Quantitative PCR (qPCR)
C) Ligation reaction

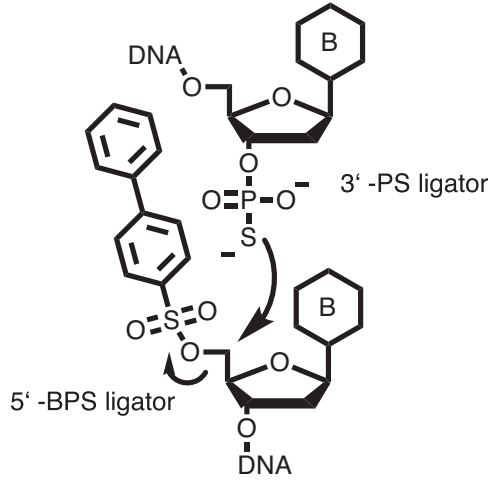

Fig. 2. A) Stereopure 2'-MOE phosphoramidites; B) Schematic representation of CLqPCR workflow; C) Chemical ligation reaction. 
A)
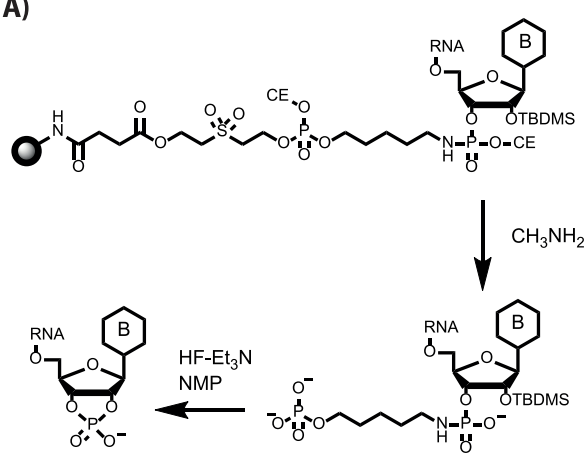

B)

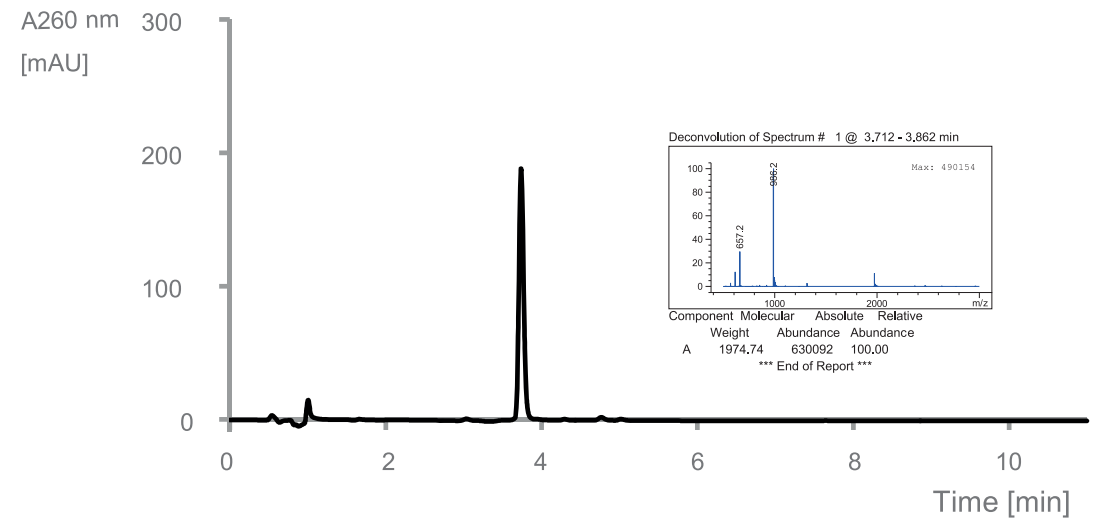

Fig. 3. A) Chemical synthesis of 2'3'-cyclic phosphate-terminated RNA. After base-mediated release of the oligonucleotide chain from the solid support, the adjacent 2'-hydroxyl group undergoes a nucleophilic attack on the phosphorus and replaces the aminoalkylphosphate moiety produced from the solid support; B) Representative LC-MS analysis of a purified 2'3'-cyclic phosphate-terminated hexaadenylate.

is compatible with RNA synthesis and purification on RP-HPLC, which is problematic using currently available chemical phosphorylation reagents, we synthesized a dinitrobenzhydryl (DNB) containing phosphoramidite (Fig. 4A). ${ }^{[19]}$ Due to its lipophilicity, a 5'-DNB group produces a shift in retention time that is comparable to that of the conventional dimethoxytrityl-group (DMT) and thus allows separation of full-length synthetic RNA from truncated failure sequences. In a second step the DNB tag is quantitatively removed under mild UV irradiation and the 5'-phosphate RNA can be ligated to the 3'-hydroxyl end of a second RNA through T4 RNA ligase. This procedure was used to obtain the bis-labelled snoRNA ACA45 (Cy3/ Cy5, 132 nt) and U6 RNA (biotin/ trioxsalen, $134 \mathrm{nt}$ ). The chemical synthesis of such long bis-labelled RNAs is of particular relevance for structural studies on highly complex RNAs. ${ }^{[20]}$

Recently, we also used this chemistry to follow a surface-reaction by ultrasensitive dynamic hyperpolarization solid-state NMR. ${ }^{[21]}$ A short RNA bearing a single 5'-terminal DNB-tagged phosphorothioate group was adsorbed to the surface of a sapphire wafer. Upon UV irradiation the characteristic ${ }^{31} \mathrm{P}$ phosphorothioate signal at $54 \mathrm{ppm}$ was lost and new spectral intensity around $20 \mathrm{ppm}$ was observed. These observations are in line with the expected cleavage of the DNB group followed by formation of a terminal disulfide linkage. ${ }^{[22]}$ Currently, we are using variants of this chemistry to functionalize SSOs with small molecules and other carrier groups designed to enhance systemic delivery.

\section{Modifications of the Ribose}

\subsection{2'-Modifications}

The furanose sugar can serve as a site of modification to introduce non-natural functionalities creating tools for RNA chemical biology. ${ }^{[23]}$ Modified RNA can be prepared by various approaches ranging from in vitro transcription to different methods of solid-phase synthesis. ${ }^{[24]}$ Site-specific modification is possible through a variety of chemical approaches and can be accomplished either pre-[25] ${ }^{[2}$ post-[26] solid-phase synthesis of the RNAs. A widely used method to insert modifications is the copper-catalyzed 1,3-dipolar azide-alkyne cycloaddition (CuAAC).[23a,26,27] The biorthogonality of azides and alkynes to biological molecules, the amenability to aqueous environments and fast reaction rates are key advantages of this modification strategy. ${ }^{[28]}$ Click (alkyne on oligonucleotide) and reverse click (azide on oligonucleotide) procedures have been reported for single or multi-homo-labelling of RNAs but were mostly hampered by low yields or limited to short RNAs. Moreover, the presence of artificially introduced labels often impedes the biological activity of the RNA. ${ }^{[29]}$ The limited knowledge regard-
A)

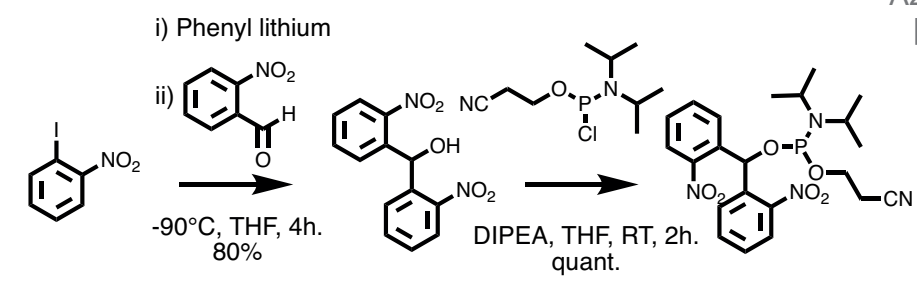

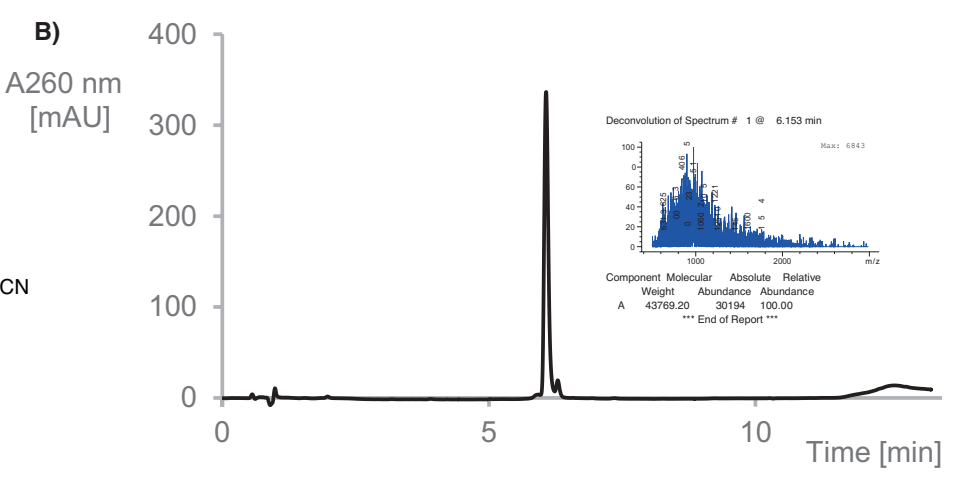

C)
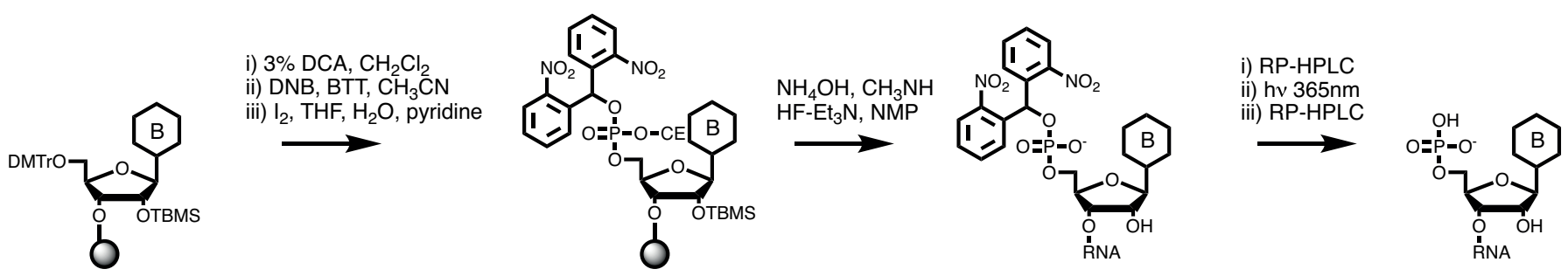

Fig. 4. A) Synthesis of the DNB phosphoramidite; B) Representative LC-MS diagram of a phosphorylated bis-labeled RNA; C) DNB-mediated 5'-terminal phosphorylation on solid support. 
ing the ideal positioning of modified nucleosides for specific applications is a serious drawback for the development of RNAbased tools for biological purposes. To address this challenge, Menzi et al. performed a systematic investigation of a position/ activity relationship for multi-labelled pre-miRNAs. ${ }^{[30]}$ The incorporation of 2'-O-propargyl adenosine, uridine or cytidine at specific sites of the pre-miRNA served as a chemical handle for the post synthetic functionalization with trioxsalen-, cyanine-3or black hole quencher-azides. Functional assessment of a set of modified miRNA precursors in dual luciferase assays provided information on optimal labelling positions. In general, labels were well-tolerated in the terminal loop region of pre-miRNA hairpins as well as in the $3 p$ arm of $5 p$ miRNAs. Labels in the central region of the $5 p$ strand or in proximity of the DICER processing site were not well tolerated. ${ }^{[30]}$

The growing interest and the poor understanding of the function of structured long non-coding RNAs propelled the development of multiple-labelled long RNAs. Hetero bis-labeling of long oligonucleotides is necessary for RNA-capturing probes that are used for the targetome-identification of specific non-coding RNAs. ${ }^{[31]}$ We have developed a method termed miRNA Crosslinking and Immunoprecipitation (miR-CLIP) which relies on dual-labelled trioxsalen/biotin miRNA precursors (Fig. 5). ${ }^{[32]}$ For this, a 2'-O-propargyl adenosine is reacted with a trioxsalen azide and incorporated during solid-phase synthesis. Subsequently, a second 2'-O-propargyl building block can be introduced site-specifically. After completion of the synthesis, the single-alkyne-modified RNA can be reacted with biotin azide on the solid support to give the bis-labelled miR-CLIP probe. Careful positioning of both functionalities is key for appropriate intracellular processing of the probe and efficient crosslinking to RNA targets inside RISC. We are currently using this approach to elucidate the targetomes of several disease-relevant miRNAs in NCCR-supported projects.

FRET measurements are usually carried out using Cy3/Cy5 groups as donor/acceptor pairs to provide structural information about the proximity of the two chromophores. ${ }^{[33]}$ The introduction of the Cy5 group is generally more demanding than their Cy3 analog due to its instability under the basic conditions employed for RNA deprotection. Therefore, an approach based on discontinuous solid-phase synthesis of pre-miRNAs was applied that involves a click reaction of a 2'- $O$-propargyl modified nucleotide within the growing RNA chain prior to the incorporation of a second alkyne-modified nucleotide. ${ }^{[34]}$ The second click reaction to introduce the Cy5 label is carried out in solution after the deprotection of the oligonucleotide. This approach prevents cross-labeling and enables the introduction of $\mathrm{Cy} 5$ modifications in solution to yield bis-modified oligonucleotides up to a length of $70 \mathrm{nts}$ in moderate to good yields $(28-67 \%)$.
More recently, we adapted a click/reverse-click procedure from Astakhova et al. ${ }^{[35]}$ as an elegant methodology for the introduction of multiple modifications in a site-specific fashion. ${ }^{[36]}$ In contrast to the methods described previously, this procedure does not require an interruption of the RNA solid-phase synthesis or the incorporation of a pre-labelled phosphoramidite for hetero bis-labelling. The approach combines the site-specific introduction of a 2'-O-propargyl nucleoside and a 2'- $O$-haloalkyl building block during the regular RNA synthesis. The bis-modified oligonucleotide on the CPG can be subjected to a first click with an azide during which only the alkyne is selectively functionalized. Subsequently, the 2'-O-haloalkyl moiety can be converted into an azide on the solid support, thereby enabling the reverse click reaction with an alkyne-modified label. Using this approach, Pradère et al. could demonstrate that the prudent insertion of Cy3 and Cy5 can be used to follow miRNA maturation. ${ }^{[36]}$ In general, labelling close to the 5'-end or the loop region of the miRNA was more efficient due to minimal steric hindrance by the CPG. ${ }^{[30,34,36]}$

\subsection{Furanose Modifications}

The use of ${ }^{13} \mathrm{C},{ }^{2} \mathrm{H}$ or ${ }^{18} \mathrm{O}$ isotope labeled furanoses is a facile and inexpensive approach to study biological functions of RNA by NMR or mass spectrometry. Isotope-labeled RNAs can be prepared by enzymatic in vitro transcription using the T7 RNA polymerase with isotope labeled nucleotides ${ }^{[37]}$ or by automated solid-phase synthesis (Fig. 6A). ${ }^{[38]}$ The advantages of chemical synthesis are the precise insertion of the labeled species, its independence of specific 5'-promoter sequences and no non-templated attachment of additional nucleotides at the 3'-end, a problem commonly observed with in vitro transcription. ${ }^{[39]}$

Crosslinking of segmentally isotope-labeled RNA and tandem mass spectrometry (CLIR-MS/MS) is a powerful tool for the precise identification for sites of protein-RNA interactions. ${ }^{[20 c]}$ This methodology combines a crosslinking of segmentally-labelled RNA with a tandem mass spectrometric analysis and enables the identification of RNA-protein interactions at nucleotide resolution. The isotopic label is essential as the identification of the interaction site strictly relies on the mass difference of the isotope-labelled and unlabeled fragments (Fig. 6). This technique identifies direct RNA-protein contacts and provides valuable insights into the spatial arrangements of RNA-protein complexes. Importantly. the methodology is not limited by the size, solubility or the ability of the RNA-protein complex to crystallize. Alternatively, methods to segmentally isotope-label RNAs for NMR studies have been employed to overcome problems related to signal degeneracy, signal assignment and to obtain high resolution structures of long oligonucleotides. ${ }^{[40]}$
A)

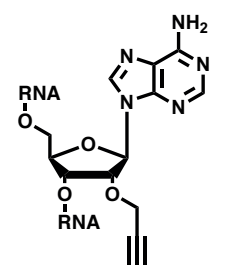

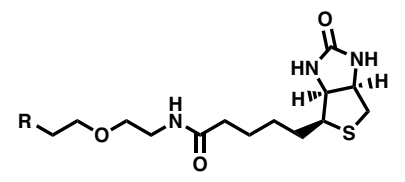

B)

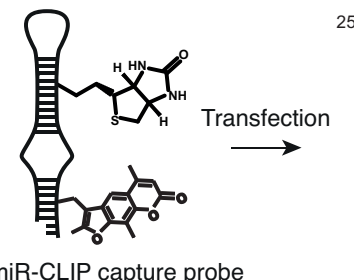

miR-CLIP capture probe

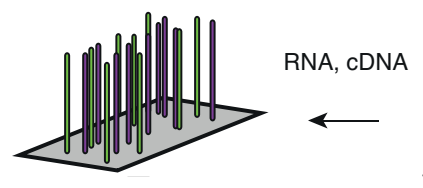

Illumina deep sequencing
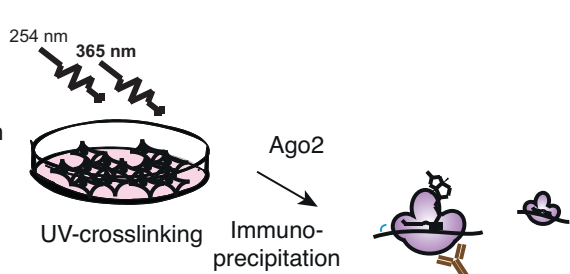
$\overbrace{\mathrm{N}}^{\mathrm{N}-\dot{\mathrm{N}}}$

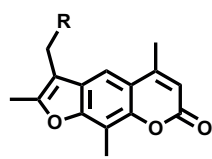

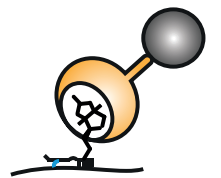

Streptavidine-biotin affinity isolation

Fig. 5. A) CuAAC of propargyl-modified nucleosides with azides for miRCLIP; B) Schematic representation of the miRCLIP protocol with the required dual-labelled pre-miRNAs. 
A)

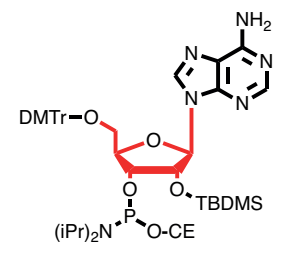

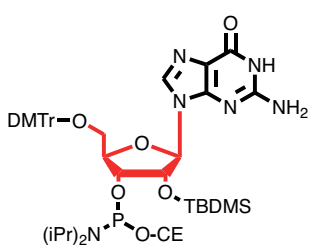
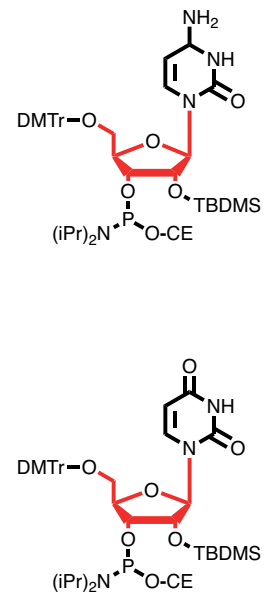

B)
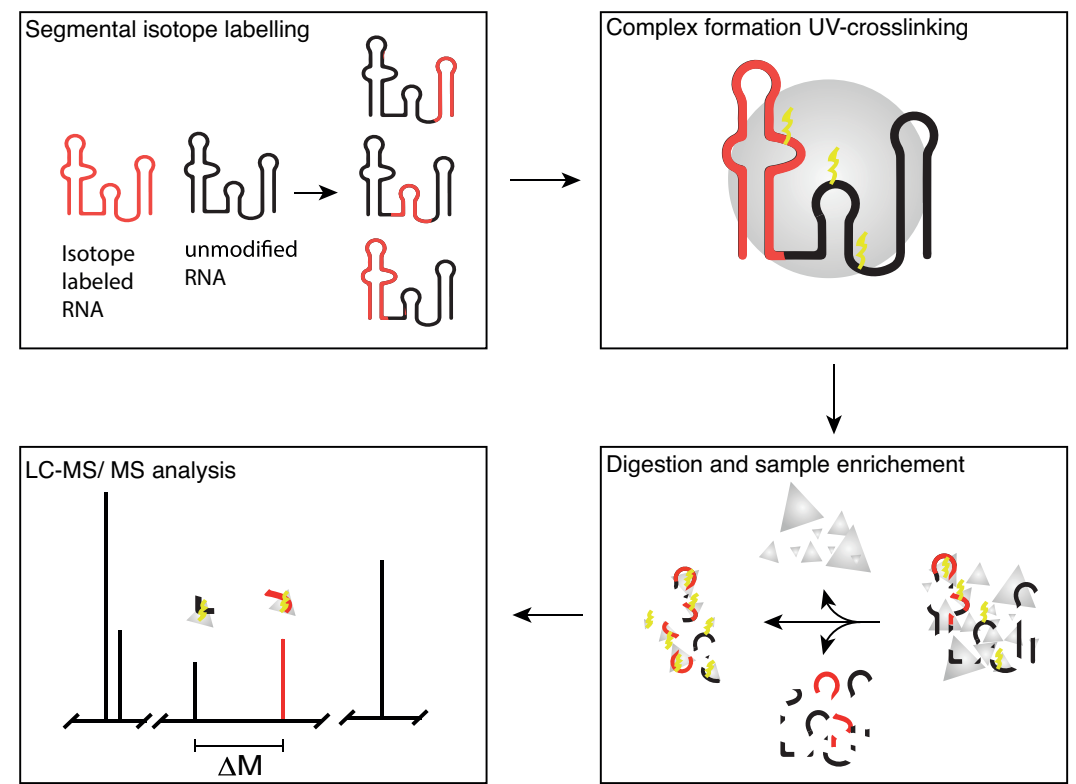

Fig. 6. A) Described ${ }^{13} \mathrm{C}$ labelled phosphoramidites; ${ }^{[38]}$ B) Schematic representation of the CLIR-MS technique. ${ }^{[20]}$ Segmentally isotope labeled RNA is crosslinked to an RNA binding protein (RBP) followed by RNAse/protease digestion, sample enrichment and LC-MS/ MS analysis. Specific isotope splitting $(\Delta M)$ in the precursor ion spectrum allows determination of RNA/ RBP interaction sites.

\section{Modifications of the Nucleobase}

\subsection{Convertible Nucleoside Approach}

Modifications of RNA at the level of the nucleobase have emerged as a critical means of translational regulation ${ }^{[41]}$ but also found use in nucleic acid-based drugs ${ }^{[42]}$ and as versatile tools in biotechnology. ${ }^{[25,43]}$ An attractive route to obtain base-modified oligonucleotides is the 'convertible nucleoside' approach. Typically, a nucleoside derivative containing a leaving group on the base is site-specifically incorporated into the RNA by solid-phase synthesis. A subsequent substitution whilst on the solid support leads to a site-specific functionalization. Since the introduction of this approach, multiple leaving groups specific for the 4-position ${ }^{[44]}$ of pyrimidines and 6-[44a,b,45] or 2-position ${ }^{[46]}$ of purines have been reported. After displacement of the leaving group by a nucleophile such as alkyl amines, the resulting nucleobase bears a modification at an exocyclic position, pointing into the major groove of a subsequently formed duplex. This is particularly interesting since RNA binding proteins generally do not bind their amino acid side chains in the major groove. We have used a convertible nucleoside approach based on $O^{4}$-triazolyluridine, initially reported by Shah et al., ${ }^{[47]}$ to obtain site-specifically cytidine $N^{4}$-methylated RNA (Fig. 7). ${ }^{[48]}$

Koch et al. ${ }^{[48 b]}$ reported an example where the convertible nucleoside approach was employed to identify critical 23S rRNA interactions in macrolide-dependent ribosome stalling. In this study,
4- $N, N$-dimethylaminocytosine (DMA) served as a non-natural nucleoside in an atomic mutagenesis approach. ${ }^{[49]}$ The systematic introduction of DMA shed light on the role of specific nucleosides of the 23S rRNA as interaction partners of the nascent polypeptide chain during translation. It was demonstrated that the universally conserved A2062, A2503 and U2586 in the 23S rRNA are essential for sensing and transmitting the stalling information within the ribosome.

\section{Conclusions and Prospects}

As our knowledge of highly complex RNA-based regulatory networks grows, so chemical tools play increasingly important roles in helping to unravel them. At the heart of these efforts are advances in solid-phase RNA synthesis and analytics, that are producing ever longer oligoribonucleotides, site-specifically substituted with an increasingly sophisticated array of reporter/ functional groups. When delivered into biological media including cells, these chemical tools mimic endogenous RNAs and enable unique data to be collected, providing new knowledge on the binding partners and functions of selected RNAs. Such projects require interdisciplinary expertises and access for biology-oriented groups to dedicated technologies in multiple areas. Therefore, the SNSF supports several RNA-focussed technology platforms, including the NCCR RNA synthesis platform which aims to fill this gap. In this review we have summarized some of the recent work of the platform that contributed to new discoveries in the RNA field.
A)

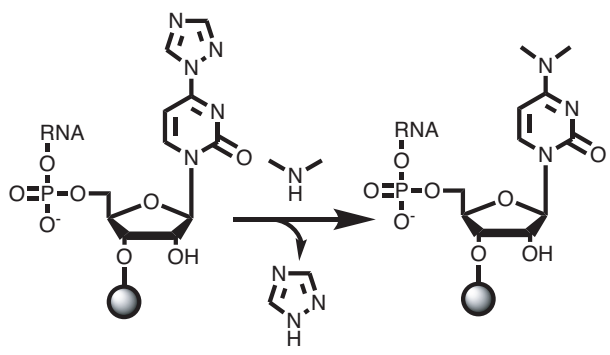

B)

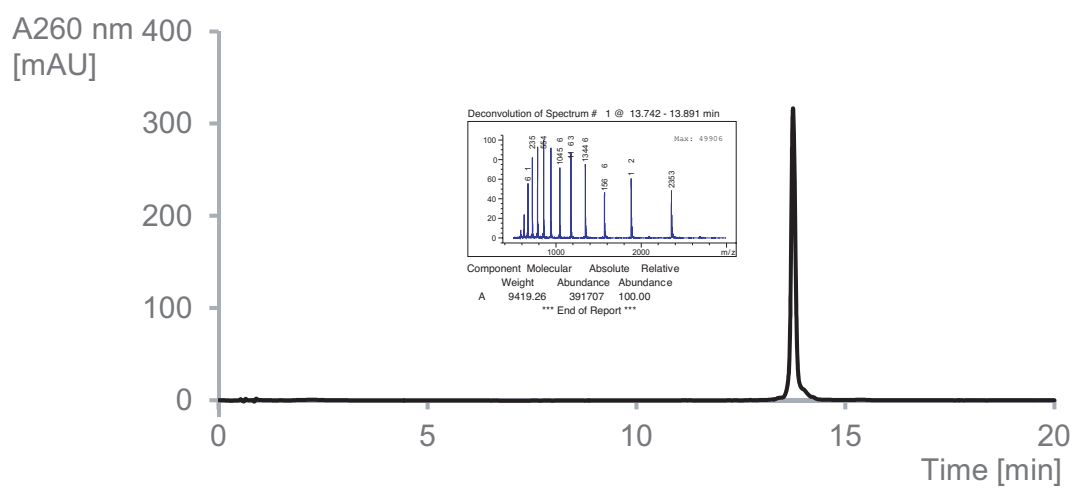

Fig. 7. A) The convertible nucleoside approach; B) LC-MS analysis of a dimethylamino-modified RNA for an atomic mutagenesis approach. 


\section{Author Contributions}

All authors, namely Pascal Röthlisberger, Christian Berk and Jonathan Hall contributed in equal parts to the conception of the article, literature collection and preparation of the manuscript.

\section{Acknowledgements}

This research was supported by the NCCR RNA \& Disease, funded by the Swiss National Science Foundation (51NF40-141735) and the Swiss National Science Foundation grant 205 321_169 612.

Received: March 1, 2019

[1] a) M. L. Stephenson, P. C. Zamecnik, Proc. Natl. Acad. Sci. USA 1978, 75 285; b) P. C. Zamecnik, M. L. Stephenson, Proc. Natl. Acad. Sci. USA 1978, 75,280 .

[2] a) C. A. Stein, D. Castanotto, Mol. Ther. 2017, 25, 1069; b) A. Khvorova, J K. Watts, Nat. Biotechnol. 2017, 35, 238.

[3] a) S. Li, C. E. Mason, Annu. Rev. Genomics Hum. Genet. 2014, 15, 127; b) M. Frye, B. T. Harada, M. Behm, C. He, Science 2018, 361, 1346.

[4] S. T. Crooke, J. L. Witztum, C. F. Bennett, B. F. Baker, Cell Metabol. 2018, 27,714 .

[5] a) M. M. Konarska, Methods 1999, 18, 22; b) A. B. Burgin, N. R. Pace, EMBO J. 1990, 9, 4111; c) S. P. Rosenstein, M. D. Been, Biochem. 1996, 35, 11403; d) K. Musier-Forsyth, P. Schimmel, Biochem. 1994, 33, 773.

[6] T. A. Watanabe, R. S. Geary, A. A. Levin, Oligonucleotides 2006, 16, 169.

[7] H. Jahns, M. Roos, J. Imig, F. Baumann, Y. Wang, R. Gilmour, J. Hall, Nat Commun. 2015, 6, 6317 .

[8] a) M. Li, H. L. Lightfoot, F. Halloy, A. L. Malinowska, C. Berk, A. Behera, D. Schümperli, J. Hall, Chem. Commun. 2017, 53, 541; b) N. Iwamoto, D. C. D. Butler, N. Svrzikapa, S. Mohapatra, I. Zlatev, D. W. Y. Sah, Meena, S. M. Standley, G. Lu, L. H. Apponi, M. Frank-Kamenetsky, J. J. Zhang, C. Vargeese, G. L. Verdine, Nat. Biotechnol. 2017, 35, 845; c) N. Oka, T. Wada, Chem. Soc. Rev. 2011, 40, 5829; d) K. W. Knouse, J. N. deGruyter, M. A. Schmidt, B. Zheng, J. C. Vantourout, C. Kingston, S. E. Mercer, I. M Mcdonald, R. E. Olson, Y. Zhu, C. Hang, J. Zhu, C. Yuan, Q. Wang, P. Park, M. D. Eastgate, P. S. Baran, Science 2018, 361, 1234.

[9] a) H. Maruyama, R. Oikawa, M. Hayakawa, S. Takamori, Y. Kimura, N. Abe G. Tsuji, A. Matsuda, S. Shuto, Y. Ito, H. Abe, Nucleic Acids Res. 2017, 45, 7042; b) J. A. Boos, D. W. Kirk, M.-L. Piccolotto, W. Zuercher, S. Gfeller, P. Neuner, A. Dattler, W. L. Wishart, F. Von Arx, M. Beverly, J. Christensen, K. Litherland, E. van de Kerkhof, P. J. Swart, T. Faller, A. Beyerbach, D. Morrissey, J. Hunziker, I. Beuvink, Nucleic Acids Res. 2013, 41, e145; c) A. Brunschweiger, L. F. R. Gebert, M. Lucic, U. Pradère, H. Jahns, C. Berk, J. Hunziker, J. Hall, Chem. Commun. 2016, 52, 156.

[10] X. Shen, D. R. Corey, Nucleic Acids Res. 2018, 46, 1584.

[11] J. K. Nair, H. Attarwala, A. Sehgal, Q. Wang, K. Aluri, X. Zhang, M. Gao, J. Liu, R. Indrakanti, S. Schofield, P. Kretschmer, C. R. Brown, S. Gupta, J. L. S. Willoughby, J. A. Boshar, V. Jadhav, K. Charisse, T. Zimmermann, K. Fitzgerald, M. Manoharan, K. G. Rajeev, A. Akinc, R. Hutabarat, M. A. Maier, Nucleic Acids Res. 2017, 45, 10969.

[12] N. T. Schirle, J. Sheu-Gruttadauria, I. J. MacRae, Science 2014, 346, 608

[13] a) M. Shigematsu, T. Kawamura, Y. Kirino, Front. Genetics 2018, 9, 562; b) K. Perumal, R. Reddy, Gene Expr. 2018, 10, 59.

[14] a) W. Filipowicz, M. Konarska, H. J. Gross, A. J. Shatkin, Nucleic Acids Res 1983, 11, 1405; b) K. K. Perkins, H. Furneaux, J. Hurwitz, Proc. Nat. Acad. Sci. USA 1985, 82, 684; c) J. Popow, M. Englert, S. Weitzer, A. Schleiffer, B. Mierzwa, K. Mechtler, S. Trowitzsch, C. L. Will, R. Lührmann, D. Söll, J. Martinez, Science 2011, 331, 760; d) B. Schwer, A. Aronova, A. Ramirez, P. Braun, S. Shuman, RNA 2008, 14, 204

[15] J. Gu, G. Shumyatsky, N. Makan, R. Reddy, J. Biol. Chem. 1997, 272, 21989

[16] W. Yang, Quart. Rev. Biophys. 2011, 44, 1.

[17] A, Laikhter, S. C. Srivastava, N. Srivastava, US patent US 8,618,279 B2, 2013

[18] a) O. Niewoehner, C. Garcia-Doval, J. T. Rostøl, C. Berk, F. Schwede, L. Bigler, J. Hall, L. A. Marraffini, M. Jinek, Nature 2017, 548, 543; b) M.
Kazlauskiene, G. Kostiuk, C. Venclovas, G. Tamulaitis, V. Siksnys, Science 2017, 357, 605 .

[19] U. Pradère, F. Halloy, J. Hall, Chem. Eur. J. 2017, 23, 5210.

[20] a) J. Willi, M. Koch, N. Polacek, J. Hall, U. Pradère, Nucleic Acids Res. 2017, 45, 6717; b) C. Leumann, D. Evéquoz, P. Küpfer, N. Polacek, J. Willi, A. Katz, G. Fernandez, Nucleic Acids Res. 2018, 46, 1945; c) G. Dorn, A. Leitner, J. Boudet, S. Campagne, C. von Schroetter, A. Moursy, R. Aebersold, F. H. T. Allain, Nat. Meth. 2017, 14, 487

[21] B. J. Walder, C. Berk, W.-C. Liao, A. J. Rossini, M. Schwarzwälder, U. Pradere, J. Hall, A. Lesage, C. Copéret, L. Emsley, ACS Cent. Sci. 2019, in press.

[22] a) T. Wu, L. E. Orgel, J. Mol. Evol. 1991, 32, 274; b) F. Eckstein, J. Am. Chem. Soc. 1966, 88, 4292.

[23] a) S. K. Jana, P. Leonard, S. A. Ingale, F. Seela, Org. Biomol. Chem. 2016 14, 4927; b) J. L. Hougland, J. A. Piccirilli, in 'Methods in Enzymology', Vol. 468, Academic Press, 2009, p. 107; c) T. Dowler, D. Bergeron, A. L. Tedeschi, L. Paquet, N. Ferrari, M. J. Damha, Nucleic Acids Res. 2006, 34 1669; d) L. Beigelman, A. Karpeisky, J. Matulic-Adamic, P. Haeberli, D. Sweedler, N. Usman, Nucleic Acids Res. 1995, 23, 4434.

[24] S. R. Das, R. Fong, J. A. Piccirilli, Curr. Opin. Chem. Biol. 2005, 9, 585.

[25] N. Rublack, H. Nguyen, B. Appel, D. Springstubbe, D. Strohbach, S. Müller, J. Nucleic Acids 2011, 805253.

[26] H.-K. Walter, B. Olshausen, U. Schepers, H.-A. Wagenknecht, Beilstein J. Org. Chem. 2017, 13, 127.

[27] a) K. H. Shaughnessy, Molecules 2015, 20, 9419; b) S. S. Pujari, F. Seela, J Org. Chem. 2012, 77, 4460.

[28] a) V. V. Rostovtsev, L. G. Green, V. V. Fokin, K. B. Sharpless, Angew. Chem. Int. Ed. 2002, 41, 2596; b) A. T. H. Le, S. M. Krylova, M. Kanoatov, S Desai, S. N. Krylov, Angew. Chem. Int. Ed. 2019, 58, 2739.

[29] D. S. Schwarz, G. Hutvágner, B. Haley, P. D. Zamore, Mol. Cell 2002, 10, 537.

[30] M. Menzi, U. Pradère, Y. Wang, M. Fischer, F. Baumann, M. Bigatti, J. Hall, ChemBioChem 2016, 17, 2012.

[31] F. C. Y. Lee, J. Ule, Mol. Cell 2018, 69, 354

[32] J. Imig, A. Brunschweiger, A. Brummer, B. Guennewig, N. Mittal, S. Kishore, P. Tsikrika, A. P. Gerber, M. Zavolan, J. Hall, Nat. Chem. Biol. 2015, 11, 107.

[33] D. Yu, P. Qin, P. V. Cornish, in 'RNA-RNA Interactions: Methods and Protocols', Ed. F. J. Schmidt, Springer New York, New York, NY, 2015, p. 97.

[34] U. Pradère, A. Brunschweiger, L. F. Gebert, M. Lucic, M. Roos, J. Hall, Angew. Chem. Int. Ed. 2013, 52, 12028.

[35] I. K. Astakhova, J. Wengel, Chemistry 2013, 19, 1112.

[36] U. Pradère, J. Hall, Bioconj. Chem. 2016, 27, 681.

[37] J. F. Milligan, D. R. Groebe, G. W. Witherell, O. C. Uhlenbeck, Nucleic Acids Res. 1987, 15, 8783 .

[38] P. Wenter, L. Reymond, S. D. Auweter, F. H. T. Allain, S. Pitsch, Nucleic Acids Res. 2006, 34, e79.

[39] C. Kao, S. Rüdisser, M. Zheng, Methods 2001, 23, 201.

[40] K. Lu, Y. Miyazaki, M. F. Summers, J. Biomol. NMR 2010, 46, 113.

[41] M. Schaefer, U. Kapoor, M. F. Jantsch, Open Biol. 2017, 7, 170077.

[42] J. Hall, Chimia 2005, 59, 803.

[43] S. Keyhani, T. Goldau, A. Blümler, A. Heckel, H. Schwalbe, Angew. Chem. Int. Ed. 2018, 57, 12017.

[44] a) C. R. Allerson, G. I. Verdine, Chem. Biol. 1995, 2, 667; b) C. R. Allerson, S. L. Chen, G. L. Verdine, J. Am. Chem. Soc. 1997, 119, 7423; c) A. M. Macmillan, G. L. Verdine, Tetrahedron 1991, 47, 2603.

[45] P. Wenter, S. Pitsch, Helv. Chim. Acta 2003, 86, 3955.

[46] a) W. T. Markiewicz, P. Godzina, M. Markiewicz, Nucleosides and Nucleotides 1999, 18, 1449; b) N. Schmid, J.-P. Behr, Tetrahedron Lett. 1995, 36, 1447; c) A. R. Diaz, R. Eritja, R. G. Garcia, Nucleosides and Nucleotides 1997, 16, 2035.

[47] K. Shah, H. Wu, T. M. Rana, Bioconj. Chem. 1994, 5, 508.

[48] a) B. Guennewig, M. Stoltz, M. Menzi, A. M. Dogar, J. Hall, Nucleic Acid Ther. 2012, 22, 109; b) M. Koch, J. Willi, U. Pradere, J. Hall, N. Polacek, Nucleic Acids Res. 2017, 45, 6717.

[49] M. D. Erlacher, A. Chirkova, P. Voegele, N. Polacek, Nat. Prot. 2011, 6, 580 . 